\title{
Effects of feedbunk restrictions and push-up frequency on the growth performance of Holstein dairy heifers offered a forage-based diet with a limit-feeding strategy
}

\author{
W. K. Coblentz, ${ }^{1 *} \odot$ M. S. Akins, ${ }^{2} \odot$ and N. M. Esser ${ }^{3} \odot$ \\ ${ }^{1}$ USDA-Agricultural Research Service, US Dairy Forage Research Center, Marshfield, WI 54449 \\ ${ }^{2}$ Department of Dairy Science, University of Wisconsin, Madison 53706 \\ ${ }^{3}$ University of Wisconsin Marshfield Agricultural Research Station, Marshfield 54449
}

\begin{abstract}
Conceptually, there are 2 feeding strategies for avoiding over-conditioning, which can be problematic for gravid dairy heifers that have reduced dietary energy density requirements relative to younger animals: (1) diluting the ad libitum-fed diet with low-energy forages; or (2) offering a diet of greater nutrient density but intentionally restricting the DM available for consumption (limit-feeding). Our objectives for this study were to evaluate the effects of feedbunk restriction and feed push-up frequency on the growth performance of gravid Holstein dairy heifers. A total of 128 Holstein heifers $(434 \pm 46.7 \mathrm{~kg})$ were enrolled in the trial. Heifers were blocked by weight, and assigned to 1 of 16 identical research pens (4 pens/weight block; 8 heifers/ pen), where the mean initial body weight $(\mathrm{BW} ; \pm \mathrm{SD})$ for the 4 blocks were $491 \pm 19.0,450 \pm 16.5,419 \pm$ $10.6,374 \pm 23.0 \mathrm{~kg}$. Within each block, a $2 \times 2$ factorial arrangement of treatments was assigned; treatments consisted of feedbunk access [full (FUL) or restricted (RES] and feed push-up frequency [1.5- or 3.0-h intervals]. The RES treatment was applied by covering 2 of the 8 head-locking feed gates in assigned pens with plywood partitions, thereby creating a feedbunk-stocking rate of $133 \%$. A total mixed ration diet composed of alfalfa haylage (60.5\%), corn silage (38.0\%), and mineral (1.5\%) was offered once daily for $91 \mathrm{~d}$; daily feed allotments (overall mean $=9.11 \mathrm{~kg}$ dry matter $(\mathrm{DM}) / \mathrm{d}$ ) were generally consumed entirely within $9 \mathrm{~h}$ of feeding. Nutrient intakes were not affected by pushup frequency or the interaction of main effects, but all intakes were affected by feedbunk access, except for DM and neutral detergent fiber expressed as a percentage of BW (overall means $=1.93$ and $0.80 \%$, respectively). In each case, intakes for FUL were greater than those
\end{abstract}

Received January 3, 2020.

Accepted March 22, 2020.

*Corresponding author: wayne.coblentz@ars.usda.gov observed for RES; for DM intake, this amounted to a difference of $0.20 \mathrm{~kg} / \mathrm{d}$ between those main-effect treatments. After $91 \mathrm{~d}$, heifers without feedbunk restriction exhibited greater final BW, but total gain and average daily gain differed only numerically between FUL and RES. Under the conditions of this trial, heifers were blocked by weight, such that BW were relatively uniform within each pen, and head-locking feed gates were used, which also provided some protection from adjacent aggressive heifers. These results suggest heifers can exhibit acceptable growth performance on high-forage diets in a limit-feeding program that includes moderate feedbunk restriction provided other forms of stress are minimized.

Key words: feedbunk access, gravid heifers, limitfeeding, push-up frequency

\section{INTRODUCTION}

Generally, management programs for dairy replacement heifers seek to minimize economic and environmental costs, while avoiding serious compromises to subsequent performance as lactating cows (Hoffman et al., 2007). Conceptually, 2 feeding strategies for achieving acceptable daily weight gains avoid the over-conditioning that can be particularly problematic for gravid heifers with reduced energy requirements relative to younger animals. For gravid heifers, these strategies include (1) diluting the ad-libitum-fed diet with low-energy forages, such as chopped straw, corn fodder, or perennial warm-season grasses (Hoffman et al., 1996; Greter et al., 2008; Coblentz et al., 2012, 2015); or (2) offering a diet of greater nutrient density, but intentionally restricting the amount of DM available for consumption (limit-feeding; Hoffman et al., 2007; Zanton and Heinrichs, 2007, 2008; Kruse et al., 2010). Several desirable characteristics have been noted with the limit-feeding approach that include greater residence time within the digestive tract, slower passage rate, greater diet digestibility, reduced fecal 
output, and improved overall feed efficiency relative to diets offered for ad-libitum intakes (Loerch, 1990; Hoffman et al., 2007; Moody et al., 2007; Zanton and Heinrichs, 2008; Kruse et al., 2010). However, Hoffman et al. (2007) reported disadvantages associated with the limit-feeding strategy that include increased vocalization and standing time by heifers, the latter of which has been associated with greater incidence of hoof disease in lactating cows (Cook et al., 2005). Tendencies for increased vocalization primarily occur just before feeding, and may subside as heifers adapt to a limit-feeding program (Hoffman et al., 2007; Zanton and Heinrichs, 2016).

Numerous cautions are associated with limit-feeding strategies. Extension recommendations (Zanton and Heinrichs, 2016) include avoiding edible bedding materials such as straw, or offering supplemental forage in auxiliary feeders because they may negate many of the advantages of limit-feeding that were described previously. Furthermore, minimization of size differences within each pen is recommended. Availability of adequate bunk space, such that all heifers can eat simultaneously, is considered an imperative component of successful management because dominant and subordinate heifers are susceptible to over- and underconditioning, respectively, when access to the feedbunk is limited. Under conditions of inadequate bunk space, use of structured impediments at the feeder, such as head-locking feed gates, or feeding twice daily at close intervals have been suggested as strategies to alleviate the potential consequences of overcrowding (Zanton and Heinrichs, 2016). Another potential remedy is to increase the frequency of feed push-up, which potentially could serve the same purpose as multiple feedings at close intervals, thereby ensuring that passive heifers have access to the TMR until the daily allotment is exhausted. To the best of our knowledge, this has not been evaluated previously. Our objectives were to evaluate the effects of feedbunk restriction and push-up frequency on the growth performance of gravid Holstein dairy heifers offered a TMR diet composed of alfalfa haylage and corn silage, the 2 most commonly available forages throughout the north-central United States.

\section{MATERIALS AND METHODS}

\section{Housing, Animals, and Diets}

Animals. All standards for animal handling and care for this experiment were authorized by the Research Animal Resources Committee (RARC) of the University of Wisconsin-Madison (Protocol \#A005189). The trial was conducted at the University of Wisconsin Marshfield Agricultural Research Station, located near
Stratford, Wisconsin, between June 12 and September 13, 2018. A total of 128 Holstein heifers $(434 \pm 46.7 \mathrm{~kg})$ were enrolled in the trial. Subsequently, heifers were blocked by weight and assigned to 1 of 16 identical research pens (4 pens/weight block; 8 heifers/pen), where the mean initial BW $( \pm \mathrm{SD})$ for the 4 blocks ( $\mathrm{n}=32$ heifers/block) were $491 \pm 19.0$ (heavy), $450 \pm$ 16.5 (medium heavy), $419 \pm 10.6$ (medium light), and $374 \pm 23.0 \mathrm{~kg}$ (light). Within each weight block, a 2 $\times 2$ factorial arrangement of treatments was assigned; treatments consisted of feedbunk access [full (FUL) or restricted (RES)] and feed push-up frequency [1.5 (90MIN) or 3.0-h (180MIN) intervals]. Standards of animal care authorized for this experiment allowed restriction of bunk space such that all heifers could not eat at once, but required an adequate number of available freestalls. As such, there was always an available freestall for each heifer. As a result of these approved standards of animal care, the effects of overcrowding at the feedbunk were effectively uncoupled from simultaneous or interacting effects of inadequate freestall numbers within the pen. In many production facilities, the effects of overcrowding at the feedbunk cannot be separated from those potentially created by inadequate numbers of free-stalls or inadequate area per heifer within the pen.

Housing. Each research pen was equipped with an automated alley-scraping system, 8 freestalls with foam-core mattresses covered with a shallow layer of dried organic solids, and 8 head-locking feeding gates. A TMR was dispersed in front of the feeding gates via a drive-through feed alley that ran through the center of the barn; with this design, each heifer had $0.61 \mathrm{~m}$ of linear bunk space, measured from center to center of adjacent head-locking gates. The RES treatment was created by attaching plywood partitions to the feed gates such that 2 gates were covered from use, which established an effective feedbunk-stocking rate of $133 \%$ within the pen. In contrast, no partitions were used for the FUL treatment, resulting in an effective feedbunk-stocking rate of $100 \%$. Throughout the trial, head-locking feeding gates were set to allow for continuous access and regress from the feedbunk, unless gates were occupied or blocked by another heifer.

Within each research pen, the total enclosed area was $84.5 \mathrm{~m}^{2} /$ pen $(7.9 \times 10.7 \mathrm{~m})$, or $10.6 \mathrm{~m}^{2} /$ heifer. Freestalls within each pen were configured in a headto-head arrangement, with each pen containing 2 rows of 4 stalls. In addition, a crossover alley in each pen facilitated movement between the 2 rows of freestalls, as well as access to the feedbunk at all times. Freestalls were bedded with a thin layer $(\sim 2 \mathrm{~cm})$ of dried organic solids approximately every $10 \mathrm{~d}$. Organic solids were generated from a common manure collection pit by 
sand removal from the freestall bedding of the adjacent lactating cow barn with a screw-type sand separator (McLanahan Corp., Holidaysburg, PA), and organic solids removal with a screen-press system (model PSS1.2-520; FAN Separator Gesellschaft, Marktschorgast, Germany). Stalls and crossover alleys were raked or scraped by hand daily to remove any feces or wet bedding soiled by urine. The timing cycle for the automated alley-scrappers was set at 2-h intervals during daylight hours, but was discontinued at night to prevent possible injury when the barn was dark.

Diet. A single experimental diet of alfalfa haylage $(60.5 \%)$, corn silage $(38.0 \%)$, and mineral $(1.5 \%)$ was offered during the trial; the associated nutrient composition for the experimental diet is summarized in Table 1 (\% of DM basis). A vertical TMR mixer (model 585; Meyer Manufacturing Corp., Dorchester, WI) was used to mix and disperse the diet at $1000 \mathrm{~h}$ daily during the 91-d feeding trial. Using an angular blade mounted on a small tractor, push-ups of remaining feed were scheduled at 3 -h intervals (1300 and $1600 \mathrm{~h}$ ) for the $180 \mathrm{MIN}$ treatment, whereas those for the 90MIN treatment were scheduled at 1.5-h intervals $(1130,1300,1430$, and 1600 h). For both push-up frequencies, any remaining feed was pushed up a final time at approximately $1900 \mathrm{~h}$, when employees exited the facility for the night. Pushup frequencies were established from previous observations of feeding behavior, in which high-forage, limit-fed diets typically were consumed or pushed out of reach within $3 \mathrm{~h}$ of feed distribution. Therefore, the 90MIN treatment essentially represented continuous feed availability until the daily allotment was exhausted, but the $180 \mathrm{MIN}$ treatment did not. Daily documentation of bunk condition by animal-care staff indicated that $83 \%$

Table 1. Ingredient composition of experimental diets and mean nutrient composition based on weekly analysis (14 wk; values $\pm \mathrm{SD})$

\begin{tabular}{|c|c|c|c|}
\hline \multirow[b]{2}{*}{ Item } & \multirow[b]{2}{*}{ TMR } & \multicolumn{2}{|c|}{ Dietary component } \\
\hline & & Alfalfa haylage & Corn silage \\
\hline \multicolumn{4}{|l|}{ Dietary forage composition ${ }^{1,2}$} \\
\hline Alfalfa haylage & 60.5 & - & - \\
\hline Corn silage & 38.0 & - & - \\
\hline Mineral & 1.5 & - & - \\
\hline \multicolumn{4}{|l|}{ Nutrient composition ${ }^{1,2}$} \\
\hline DM & $40.8 \pm 5.71$ & $48.7 \pm 9.88$ & $36.1 \pm 2.05$ \\
\hline $\mathrm{CP}$ & $14.1 \pm 0.70$ & $18.0 \pm 1.32$ & $6.7 \pm 0.62$ \\
\hline NDICP $^{3}$ & $2.07 \pm 0.308$ & $2.67 \pm 0.511$ & $1.22 \pm 0.524$ \\
\hline $\mathrm{ADICP}^{3}$ & $0.82 \pm 0.198$ & $0.89 \pm 0.209$ & $0.66 \pm 0.084$ \\
\hline $\mathrm{NDF}^{4}$ & $41.7 \pm 1.56$ & $42.0 \pm 2.79$ & $42.4 \pm 3.24$ \\
\hline NDF digestibility, $\%$ of $\mathrm{NDF}^{5}$ & $55.0 \pm 3.90$ & $50.0 \pm 5.87$ & $62.4 \pm 3.25$ \\
\hline $\mathrm{ADF}^{3} \mathrm{O}$ & $29.3 \pm 3.13$ & $32.1 \pm 4.05$ & $25.2 \pm 2.23$ \\
\hline $\mathrm{ADL}^{3}$ & $3.61 \pm 1.639$ & $4.59 \pm 2.109$ & $1.80 \pm 0.757$ \\
\hline Starch $^{3}$ & $14.0 \pm 3.18$ & $3.4 \pm 1.75$ & $28.7 \pm 4.38$ \\
\hline Ether extract & $2.41 \pm 0.329$ & $2.47 \pm 0.394$ & $2.27 \pm 0.350$ \\
\hline Ash & $10.3 \pm 0.62$ & $11.4 \pm 1.01$ & $4.7 \pm 0.61$ \\
\hline $\mathrm{P}$ & $0.33 \pm 0.027$ & $0.36 \pm 0.050$ & $0.21 \pm 0.064$ \\
\hline $\mathrm{Ca}$ & $0.59 \pm 0.090$ & $0.61 \pm 0.130$ & $0.15 \pm 0.037$ \\
\hline $\mathrm{K}$ & $2.32 \pm 0.212$ & $3.14 \pm 0.551$ & $0.84 \pm 0.172$ \\
\hline $\mathrm{Mg}$ & $0.25 \pm 0.029$ & $0.26 \pm 0.058$ & $0.10 \pm 0.017$ \\
\hline \multicolumn{4}{|l|}{ Energy calculations ${ }^{6}$} \\
\hline TDN & $63.0 \pm 2.44$ & $59.4 \pm 3.96$ & $71.3 \pm 2.16$ \\
\hline ME, Mcal/kg & $2.35 \pm 0.109$ & $2.19 \pm 0.176$ & $2.73 \pm 0.096$ \\
\hline $\mathrm{NE}_{\mathrm{M}}, \mathrm{Mcal} / \mathrm{kg}$ & $1.48 \pm 0.098$ & $1.33 \pm 0.160$ & $1.80 \pm 0.082$ \\
\hline $\mathrm{NE}_{\mathrm{G}}, \mathrm{Mcal} / \mathrm{kg}$ & $0.89 \pm 0.088$ & $0.75 \pm 0.145$ & $1.18 \pm 0.072$ \\
\hline
\end{tabular}

${ }^{1}$ All ingredients or nutrients are expressed on a $\%$ of DM basis unless otherwise noted.

${ }^{2}$ Mineral package contained $60.8 \%$ feed-grade lime, $15.0 \%$ salt, $9.35 \%$ ClariFly $(0.67 \%$; Wellmark International Ltd., Dallas, TX), $5.00 \%$ manganese oxide, $2.10 \%$ sulfur, $1.60 \%$ selenium $1600,1.55 \%$ vitamin A 30000, $0.90 \%$ magnesium sulfate (32\%), $0.80 \%$ zinc sulfate, $0.675 \%$ vitamin E (50\%), $0.650 \%$ copper sulfate, $0.500 \%$ mineral oil, $0.500 \%$ vitamin $\mathrm{D}, 0.325 \%$ iodine mix, $0.025 \%$ cobalt carbonate $(46 \%)$, and $0.225 \%$ thiamine mono-nitrate (99\%). Mineral package was blended into the total diet and delivered within the TMR.

${ }^{3}$ Concentrations of ADF, ADL, starch, neutral detergent insoluble CP (NDICP), and acid detergent insoluble CP (ADICP) were determined for wk 1, 5, 9, and 13 of the trial. Calculated SD of each analyte is based on 4 observations.

${ }^{4}$ Neutral-detergent solution contained both heat-stable $\alpha$-amylase and sodium sulfite.

${ }^{5} \mathrm{NDF}$ digestibility determined following a 48-h digestion in buffered rumen fluid.

${ }^{6}$ Energy calculations based on NRC (2001). 
of the feedbunks were completely void of feed by 1900 h. As such, final push-up at $1900 \mathrm{~h}$ typically affected only minimal amounts of feed that had previously been pushed out of reach by heifers.

Daily Feed Allotments. The common diet formulated for the present study was composed exclusively of alfalfa haylage (60.5\%), corn silage $(38.0 \%)$, and mineral (1.5\%) (Table 1), which included the 2 forages most commonly available to dairy producers throughout the Midwest. Furthermore, diets of this type offered to gravid heifers for ad libitum intake have consistently resulted in excessive weight gains $(\geq 1.09$ $\mathrm{kg} / \mathrm{d}$; Coblentz et al., 2012, 2015) and subsequent over-conditioning, thereby requiring inclusion of lowquality, highly fibrous diluting forages to reduce weight gains to acceptable daily targets. The concentration of NDF within this experimental diet $(41.7 \pm 1.56 \%)$ is consistent with concentrations of NDF within previous alfalfa haylage/corn silage diets evaluated at this research station (Coblentz et al., 2012, 2015), and suggests limitation of energy intake would be required to prevent excessive weight gains. Previously, Hoffman et al. (2008) suggested that voluntary intakes for dairy heifers are restricted by gut fill when about $1 \%$ of BW is consumed as NDF; for a $454-\mathrm{kg}$ heifer, that would equate to $10.9 \mathrm{~kg} / \mathrm{d}$ of DMI, or $25.6 \mathrm{Mcal} / \mathrm{d}$ of $\mathrm{ME}$, both of which exceed requirements for an $0.8 \mathrm{~kg} / \mathrm{d}$ growth target (NRC, 2001).

Per extension management recommendations (Zanton and Heinrichs, 2016), daily dietary allotments of DM were set initially to supply ME at $235 \mathrm{kcal} / \mathrm{kg}$ of metabolic body weight $\left(\mathrm{BW}^{0.75}\right)$, and were thereby projected to support daily weight gains consistent with common targets for Holstein heifers $(0.86-0.91 \mathrm{~kg} / \mathrm{d})$. Refinements to daily feed allotments were made as needed based on interim trial weights of all heifers taken on d 47 and 77 of the trial. Adjustments to daily feed allotments based on interim BW were made by weight class (block), such that all 4 pens within a weight class always received the same adjustment. By the conclusion of the trial, daily allotments of energy (ME) were reduced from the initial $235 \mathrm{kcal} / \mathrm{kg}$ of $\mathrm{BW}^{0.75}$ by 15 , 25,35 , and $40 \mathrm{kcal} / \mathrm{kg}$ of $\mathrm{BW}^{0.75}$ for light, medium light, medium heavy, and heavy weight classes, respectively, to meet acceptable growth targets. Considered over all weight classes and treatments, the mean daily allotment of $\mathrm{ME}$ for the entire trial was $210 \mathrm{kcal} / \mathrm{kg}$ of $\mathrm{BW}^{0.75}$. In addition, micro-adjustments to dietary allotments were made weekly based on expected weight gains, as well as regular (weekly) laboratory analyses of the experimental diet. The dietary concentration of CP (14.1 $\pm 0.70 \%)$ was consistent with limit-feeding recommendations for post-pubertal heifers (13-14\%; Hill et al.,
2013; Zanton and Heinrichs, 2016). In a review, Hill et al. (2013) summarized that heifers between breeding and calving should be offered diets with 53 to $56 \mathrm{~g}$ of $\mathrm{CP} /$ Mcal of ME, which was exceeded in this study (60 g of CP/Mcal of ME), and similar to NRC (2001) requirements for heifers of this size with comparable ADG targets.

\section{Laboratory Analysis of Diets}

Diet samples $(\sim 400 \mathrm{~g})$ were obtained daily, stored at $-20^{\circ} \mathrm{C}$ in sealed plastic bags, and then composited by week for subsequent nutritive analysis. After diet samples obtained throughout each week were thawed and thoroughly mixed, a subsample $(\sim 400 \mathrm{~g})$ was dried to constant weight $(\sim 96 \mathrm{~h})$ under forced air at $55^{\circ} \mathrm{C}$ to determine the concentrations of DM within these weekly composites. Dried weekly diet composites were ground through a 1-mm screen in a Thomas Wiley mill (model 4; Thomas Scientific, Swedesboro, NJ) and then analyzed by the University of Wisconsin Soil and Forage Laboratory (Marshfield, WI). Each sample was analyzed for (1) ash, following combustion for $6 \mathrm{~h}$ in a muffle furnace at $500^{\circ} \mathrm{C} ;(2) \mathrm{OM}(\%)$, calculated as 100 - \% ash; (3) CP, by macro-Kjeldahl methodology (AOAC International, 1998; method 988.05); (4) calcium, $\mathrm{K}$, and $\mathrm{Mg}$ by atomic absorption spectroscopy; (5) phosphorus, colorimetrically (Schulte et al., 1987); (6) starch (model 2700D, Yellow Springs Instrument Co., Yellow Springs, OH); and (7) fat (AOAC, 1990; method 920.29). For analysis of Ca, K, Mg, and P, 0.50$\mathrm{g}$ samples were prepared by ashing in a muffle furnace at $500^{\circ} \mathrm{C}$ for $2 \mathrm{~h}$, followed by the subsequent colorimetric or atomic absorption procedures as described by Peters (2013). Concentrations of NDF were determined by the methods of Goering and Van Soest (1970) with heatstable $\alpha$-amylase and sodium sulfite included within the NDF solution. Furthermore, additional analyses (ADF and ADL) were performed as described by Goering and Van Soest (1970) during wk 1, 5, 9, and 13 of the trial without preliminary digestions in neutral detergent. On an identical schedule, and following direct digestions in neutral- and acid-detergent solutions, fiber residues were also analyzed for residual $\mathrm{CP}$ by the identical Kjeldahl methodology described for determination of $\mathrm{CP}$. For neutral detergent insoluble $\mathrm{CP}$, no sodium sulfite was included in the preliminary digestion in neutral detergent to avoid excessive solubilization of CP from the residual forage fiber (Van Soest et al., 1991). In addition, an in vitro determination of NDF digestibility was conducted in buffered rumen fluid for 48 h (Kruse et al., 2010; Coblentz et al., 2012), and was used to calculate truly digestible fiber as a component 
part of the summative model (NRC, 2001) that was used subsequently to estimate energy density as TDN. Other measures of energy $\left(\mathrm{ME}, \mathrm{NE}_{\mathrm{G}}\right.$, and $\left.\mathrm{NE}_{\mathrm{M}}\right)$ were calculated as recommended by NRC (2001).

\section{Body Measurements}

The body condition scoring system of Wildman et al. (1982) was used to assess heifer body condition at the beginning and end of the trial. Each heifer was scored (scale: $1-5$ ) by 2 trained evaluators where $1=$ emaciated and $5=$ obese; increments of 0.5 units were applied to best describe the body condition of each heifer. The initial BW for each enrolled heifer was calculated from weights obtained on 3 consecutive days using a cattle chute (Real Tuff, Clearbrook, MN) equipped with an electronic scale (Tru-Test Inc., Mineral Wells, TX). All weights were obtained each morning immediately before feed was delivered. Final heifer BW were obtained similarly, on 3 consecutive days, after the 91-d feeding trial was completed. Once during the initial and once during the final 3-d weighing periods, each heifer was measured for heart girth, body length, hip height, and hip width (Esser et al., 2009).

\section{Hygiene Assessments}

During the trial, all heifers were scored 3 times for hygiene of flanks and legs using the 4-point system of Cook and Reinemann (2007), where $1=$ free from manure and $4=$ covered with caked-on manure. Scores were taken on d 33, 66, and 90 of the trial by 2 trained technicians; therefore, each heifer was scored 6 times during the trial. Scores were averaged across the 3 evaluation dates and 2 observers to calculate the final hygiene score for each heifer. The mean differences between evaluator assessments for hygiene were $0.2 \pm$ 0.18 for flanks and $0.6 \pm 0.27$ for legs, based on $(\mathrm{n}=$ 48) combinations of pen and evaluation period.

\section{Statistics}

The experiment was designed as a randomized complete block with a $2 \times 2$ factorial arrangement of treatments that included feedbunk access (RES or FUL) and push-up frequency (90MIN or 180MIN). As noted previously, the blocking factor was weight class (4 blocks), created on the basis of initial BW. The research pen served as the experimental unit (St-Pierre, 2007), thereby permitting 15 total degrees of freedom. Under the conditions of this experiment, blocks (replications) were considered to be a fixed effect because heifers were blocked initially on the basis of BW. In all cases, sta- tistical analyses were conducted with PROC MIXED of SAS (version 9.4, https://www.sas.com/en_us/home .html). Across all response variables, there was little evidence of an interaction between feedbunk access and push-up frequency; therefore, only main-effect means are presented and discussed. Statistical significance of main effects was declared at $P<0.05$, with trends of interest described at $P<0.10$.

\section{RESULTS AND DISCUSSION}

\section{Nutrient Intakes}

Dry matter, NDF, and energy intakes (Table 2) were not affected by push-up frequency $(P \geq 0.250)$ or the interaction of main effects $(P \geq 0.811)$. In contrast, all nutrient intakes were affected $(P \leq 0.024)$ by feedbunk access, except for DM expressed as a percentage of BW (overall mean $=1.93 \% ; P=0.836)$, and for NDF expressed on the same basis $(0.80 \% ; P=0.982)$. In each case, intakes for FUL were greater than those observed for RES; for DMI, this amounted to a difference of 0.20 $\mathrm{kg} / \mathrm{d}(P=0.024)$ between the 100 and $133 \%$ feedbunkstocking rates. Although the greater nutrient intakes observed for FUL tend to corroborate recommendations by Zanton and Heinrichs (2016) that all heifers should be able to eat simultaneously, the magnitude of difference in DMI between FUL and RES was relatively small. This difference may partially be related to a small $(7-\mathrm{kg})$ tendency for difference in initial heifer BW between the FUL and RES main-effect treatments $(P$ $=0.073$; Table 2); however, differences in DMI between FUL and RES were eliminated, and essentially nil (1.92 vs. $1.93 \%$ of BW), when expressed on a percentage of BW basis. Although the ad libitum voluntary intake of the experimental diet was not assessed in this trial, gravid heifers that were offered a similar alfalfa-corn silage diet at $85 \%$ of ad libitum intake exhibited ADG of $0.88 \mathrm{~kg} / \mathrm{d}$ compared with $1.09 \mathrm{~kg} / \mathrm{d}$ for control heifers offered the same diet without restriction (Coblentz et al., 2012). Based on the DMI of those negative-control heifer groups (2.21\% of BW), the restricted DMI offered in the present study were similar to the previous $85 \%$ target.

Significant differences $(P \leq 0.030)$ between FUL and RES for intakes of other nutrients (data not shown) were primarily an artifact of the noted difference in DMI, and although statistically significant, their magnitude was generally of questionable practical relevance. Across all treatments, the mean intake of $\mathrm{N}$ averaged $2.02 \mathrm{~g}$ of $\mathrm{N} / \mathrm{kg}$ of $\mathrm{BW}^{0.75}$, which exceeded the $1.67 \mathrm{~g}$ of $\mathrm{N} / \mathrm{kg}$ of $\mathrm{BW}^{0.75}$ threshold at which $\mathrm{N}$ retention is maximized (Zanton and Heinrichs; 2009); similarly, the 
overall mean ME intake for this study was $210 \mathrm{kcal} / \mathrm{kg}$ of $\mathrm{BW}^{0.75}$, which was about $10.6 \%$ less than the recommended $235 \mathrm{kcal} / \mathrm{kg}$ of $\mathrm{BW}^{0.75}$.

\section{Heifer Growth and Performance}

On a pretrial basis, mean hip width (Table 2) was marginally greater (48 vs. $47 \mathrm{~cm} ; P=0.043$ ) and initial BW tended to be greater (437 vs. $430 \mathrm{~kg} ; P=0.073$ ) for FUL compared with RES, but no other initial body measurement differed on the basis of feedbunk access $(P \geq 0.151)$. Similarly, small initial differences were observed between 90MIN and 180MIN for hip height (138 vs. $140 \mathrm{~cm} ; P \geq 0.008)$ and heart girth (183 vs. $179 \mathrm{~cm} ; P=0.001)$. No other comparisons of push-up frequencies for initial body measurements approached significance $(P \geq 0.251)$. Interactions of main effects were not detected $(P \geq 0.270)$, except for a tendency $(P=0.061)$ observed for heart girth .

At the conclusion of the 91-d feeding trial, there were no interactions of main effects for any final body measurement $(P \geq 0.123)$. Feedbunk access affected $(P=0.048)$ final BW, with FUL exhibiting a $15-\mathrm{kg}$ advantage over RES. Tendencies for greater final body measurements were observed in heifers managed with FUL compared with RES for hip width (52 vs. $51 \mathrm{~cm}$; $P=0.097$ ), hip height (146 vs. $145 \mathrm{~cm} ; P=0.065)$, and BCS (3.35 vs. $3.28 ; P=0.064)$, but the magnitude of these tendencies was very small. Push-up frequency affected $(P=0.009)$ final hip height, with $90 \mathrm{MIN}$ greater than 180MIN (192 vs. $190 \mathrm{~cm}$ ), but no other final body measurement exhibited statistical significance $(P \geq$

Table 2. Effects of feedbunk access and frequency of feed push-up on nutrient intakes, body measurements, and growth performance of Holstein replacement heifers

\begin{tabular}{|c|c|c|c|c|c|c|c|c|}
\hline \multirow[b]{2}{*}{ Item } & \multicolumn{2}{|c|}{ Feedbunk $^{1}$} & \multicolumn{2}{|c|}{ Push-up ${ }^{2}$} & \multirow[b]{2}{*}{ SEM } & \multicolumn{3}{|c|}{ Effect $^{3}$} \\
\hline & Full access & Restricted & $1.5 \mathrm{~h}$ & $3.0 \mathrm{~h}$ & & Feedbunk & Push-up & Interaction \\
\hline $\mathrm{DM}, \mathrm{kg} / \mathrm{d}$ & 9.21 & 9.01 & 9.15 & 9.06 & 0.052 & 0.024 & 0.264 & 0.868 \\
\hline $\mathrm{DM}^{4} \%$ of $\mathrm{BW}$ & 1.92 & 1.93 & 1.92 & 1.93 & 0.008 & 0.836 & 0.836 & 0.999 \\
\hline $\mathrm{NDF}, \mathrm{kg} / \mathrm{d}$ & 3.84 & 3.75 & 3.81 & 3.78 & 0.022 & 0.022 & 0.285 & 0.875 \\
\hline $\mathrm{NDF}^{4} \%$ of BW & 0.80 & 0.80 & 0.80 & 0.80 & 0.004 & 0.982 & 0.909 & 0.982 \\
\hline \multicolumn{9}{|c|}{ Initial body measurement } \\
\hline $\mathrm{BW}, \mathrm{kg}$ & 437 & 430 & 435 & 432 & 2.5 & 0.073 & 0.498 & 0.461 \\
\hline Length, cm & 143 & 142 & 142 & 143 & 0.8 & 0.915 & 0.348 & 0.461 \\
\hline Hip width, cm & 48 & 47 & 48 & 48 & 0.3 & 0.043 & 0.999 & 0.270 \\
\hline Hip height, cm & 139 & 139 & 138 & 140 & 0.5 & 0.469 & 0.008 & 0.999 \\
\hline Heart girth, cm & 182 & 181 & 183 & 179 & 0.6 & 0.151 & 0.001 & 0.061 \\
\hline BCS & 3.22 & 3.22 & 3.20 & 3.25 & 0.028 & 0.927 & 0.251 & 0.831 \\
\hline Heart girth, cm & 191 & 190 & 192 & 190 & 0.4 & 0.570 & 0.009 & 0.849 \\
\hline BCS & 3.35 & 3.28 & 3.29 & 3.33 & 0.024 & 0.064 & 0.246 & 0.528 \\
\hline \multicolumn{9}{|l|}{ Growth } \\
\hline Weight gain, kg & 86.5 & 79.5 & 86.0 & 80.0 & 2.94 & 0.130 & 0.183 & 0.461 \\
\hline $\mathrm{ADG}, \mathrm{kg} / \mathrm{d}$ & 0.94 & 0.86 & 0.94 & 0.87 & 0.032 & 0.124 & 0.189 & 0.433 \\
\hline $\mathrm{CV},{ }^{6} \%$ & 19.3 & 18.2 & 18.4 & 19.0 & 1.67 & 0.646 & 0.806 & 0.728 \\
\hline Length, cm & 7.8 & 8.4 & 8.8 & 7.3 & 0.70 & 0.560 & 0.171 & 0.483 \\
\hline Hip width, cm & 3.2 & 3.5 & 3.2 & 3.5 & 0.24 & 0.498 & 0.342 & 0.692 \\
\hline Hip height, cm & 6.7 & 5.9 & 7.5 & 5.1 & 0.45 & 0.273 & 0.004 & 0.954 \\
\hline Heart girth, cm & 8.8 & 9.9 & 8.4 & 10.4 & 0.73 & 0.308 & 0.079 & 0.117 \\
\hline BCS & 0.13 & 0.06 & 0.09 & 0.09 & 0.037 & 0.221 & 0.908 & 0.799 \\
\hline Feed:gain, kg:kg & 9.8 & 10.5 & 9.9 & 10.3 & 0.35 & 0.195 & 0.371 & 0.423 \\
\hline
\end{tabular}

${ }^{1}$ Feedbunk: full access $=$ one head-locking gate per heifer ( 8 head-locking gates, 8 heifers); restricted $=$ feedbunk-stocking rate set at $133 \%$ of capacity (6 head-locking gates, 8 heifers).

${ }^{2}$ Push-up: $1.5 \mathrm{~h}=$ feed pushed up at 1.5-h intervals $(1130,1300,1430,1600 \mathrm{~h})$, with a final push-up of any residual feed at $1900 \mathrm{~h} ; 3.0 \mathrm{~h}=$ feed pushed up at 3.0-h intervals $(1300$ and $1600 \mathrm{~h}$ ), with a final push-up of any residual feed at $1900 \mathrm{~h}$. All feed was delivered once daily at $1000 \mathrm{~h}$.

${ }^{3}$ Tests of significance for feedbunk access and push-up frequency main effects, and their interaction.

${ }^{4}$ Calculation based on mean BW during the trial [(initial BW + final BW $) / 2$ ].

${ }^{5}$ Energy calculations based on NRC (2001).

${ }^{6} \mathrm{ANOVA}$ using the $\mathrm{CV}$ for ADG obtained from each research pen as the response variable. 
0.214). A 9-kg final BW advantage was observed for 90MIN compared with $180 \mathrm{MIN}$, but this difference was only numerical in nature $(P=0.214)$.

Feedbunk access did not affect any measure of growth $(P \geq 0.124)$, nor any interaction of main effects $(P \geq 0.117)$. Push-up frequency affected $(P=0.004)$ increases in hip height, where $90 \mathrm{MIN}$ was greater than 180MIN (7.5 vs. $5.1 \mathrm{~cm}$ ), and there was a tendency $(P$ $=0.079$ ) for greater increases in heart girth for $180 \mathrm{MIN}$ compared with $90 \mathrm{MIN}(10.4$ vs. $8.4 \mathrm{~cm})$. While detection of significant effects for various indices of growth was limited, several trends are worthy of note. Numerically greater weight gains were observed in response to both management factors evaluated, which included a $7.0-\mathrm{kg}$ advantage for FUL compared with RES $(P=$ 0.130 ) and a $6.0-\mathrm{kg}$ advantage for 90MIN compared with 180MIN $(P=0.183)$. Corresponding numerical advantages for FUL $(0.08 \mathrm{~kg} / \mathrm{d})$ and $90 \mathrm{MIN}(0.07 \mathrm{~kg} / \mathrm{d})$ were observed for ADG $(P \leq 0.189)$. Overall, ADG for all main-effect treatments ranged narrowly from 0.86 to $0.94 \mathrm{~kg} / \mathrm{d}$, which is similar to other growth rates for large-breed heifers that were limit-fed high-forage diets (Hoffman et al., 2007; Kruse et al., 2010; Coblentz et al., 2012), and generally align with common growth targets for Holstein heifers (Hoffman, 1997; Kertz et al., 1998).

Several studies (Longenbach et al., 1999; Greter et al., 2010; Kitts et al., 2011) have used measures of variation within pen replicates as a response variable to assess undesirable variability in growth performance among heifers within a common pen. For the present study, a coefficient of variation $(\mathbf{C V}, \%)$ for ADG was calculated for each pen and evaluated as a response variable to assess the variability of weight-gain rates across treatments. From a management perspective, ensuring adequate bunk space such that all heifers can eat simultaneously has been described as "imperative" within extension recommendations for limit-feeding heifers (Zanton and Heinrichs, 2016). With restricted feedbunk access, dominant and subordinate heifers might be expected to over- and under-perform, respectively, thereby increasing variability of weight gains within the pen. DeVries and von Keyserlingk (2009) have concluded that competition for feed by growing dairy heifers generally alters feeding behaviors, including tendencies for increased variation in day-to-day behaviors. However, the 2 management effects evaluated in this trial had little effect on within-pen variabilities for ADG; calculated CV ranged narrowly across maineffect means from 18.2 to $19.3 \%$, yielding no significant effects $(P \geq 0.646)$. This limited and consistent variation within pens across treatment effects may be explained in part by the experimental design that included blocking on initial BW, as well as use of headlocking feed gates, which provide some protection from displacement by aggressive or disproportionately large heifers within the pen. Both of these factors have been mentioned as possible remedies for inadequate bunk space in limit-feeding situations (Zanton and Heinrichs, 2016). Previously, Huzzey et al. (2006) concluded that lactating cows were displaced from the feedbunk more frequently when post-and-rail feed barrier systems were used compared with a system that provided some protection and physical separation from adjacent cows, such as head-locking gates; it was also concluded that displacements were more frequent among cows ranked lower in social hierarchy when the post-and-rail system was used, particularly when there were high-stocking densities within the pen. Two additional factors may have further limited differences in variability within pens with respect to growth performance. First, the TMR offered in this trial was generally available to heifers for about $9 \mathrm{~h}$ daily, which does not constitute the more restrictive limits that might be associated with inclusion of concentrate feeds. Second, variability in heifer growth responses associated with sorting dietary components is unlikely; heifers offered a TMR comprised solely of alfalfa haylage and corn silage in a previous experiment exhibited minimal sorting based on proportions of various particle sizes remaining in the feedbunk as a function of time from feeding (Coblentz et al., 2015).

\section{Hygiene}

Hygiene scores (Table 3) were not affected by feedbunk access in assessments of flanks (overall mean $=$ $1.16 ; P=0.951$ ) or legs (overall mean $=1.51 ; P=$ $0.490)$; however, a small difference was detected between the 90MIN and 180MIN push-up frequencies for flanks (1.21 vs. $1.10 ; P=0.033)$. There were no interactions of main effects $(P \geq 0.311)$. The objectives of this trial sought to evaluate potential remedies for a specific caution against overcrowding within limitfeeding management systems (Zanton and Heinrichs, 2016). As such, documentation of high standards of animal care is important. Within that context, these scores indicate relatively good cleanliness that could not be related to any competition by heifers at the feedbunk in association with feedbunk restriction or limit-feeding management. Scores for these assessments were $\leq 1.53$ on a scale of 1 to 4 , where $1=$ no dirt and $2=$ only minor splashing, documenting high standards of general animal care in which heifers did not lose their footing or fall to the floor during competition at the feedbunk. 
Table 3. Hygiene scores ${ }^{1}$ for legs and flanks as affected by feedbunk access and frequency of feed push-up for Holstein dairy heifers

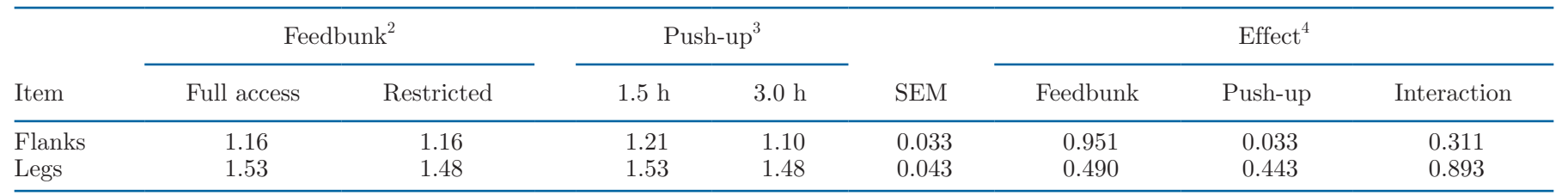

${ }^{1}$ Hygiene scores were assessed on a scale of $1=$ no manure, to $4=$ caked on manure (Cook and Reinemann, 2007).

${ }^{2}$ Feedbunk: full access $=1$ head-locking gate per heifer ( 8 head-locking gates, 8 heifers); restricted $=$ feedbunk-stocking rate set at $133 \%$ of capacity (6 head-locking gates, 8 heifers).

${ }^{3}$ Push-up: $1.5 \mathrm{~h}=$ feed pushed up at 1.5-h intervals $(1130,1300,1430,1600 \mathrm{~h})$, with a final push-up of any residual feed at $1900 \mathrm{~h} ; 3.0 \mathrm{~h}=$ feed pushed up at 3.0-h intervals (1300 and $1600 \mathrm{~h}$ ), with a final push-up of any residual feed at $1900 \mathrm{~h}$. All feed was delivered once daily at $1000 \mathrm{~h}$.

${ }^{4}$ Tests of significance for feedbunk access and push-up frequency main effects, and their interaction.

\section{CONCLUSIONS}

The frequency of feed push-ups within a limit-feeding management system affected growth performance of gravid heifers only minimally throughout this research trial, and did not interact with feedbunk access, where restriction was set at 100 or $133 \%$ of capacity. After 91 $d$, heifers without feedbunk restriction exhibited greater final BW, but total gain and ADG did not differ between FUL and RES. These results suggest heifers can exhibit acceptable growth performance when offered a high-forage diet with limit-feeding management that includes moderate feedbunk restriction, provided other forms of stress are minimized. Under the conditions of this trial, heifers were blocked by weight, such that BW were relatively uniform within each pen, and headlocking feed gates were used, both of which provided additional protection from adjacent disproportionately large or aggressive heifers. Under these conditions, gravid heifers were mostly able to adapt to restricted bunk space and exhibit acceptable daily weight gains, regardless of feed push-up frequency. There were no significant differences in CV (\%) across treatments for ADG within pens, indicating that common concerns about dominant and submissive heifer behaviors and their effects on growth performance were minimized. Although moderate feedbunk restriction did not affect heifer growth performance in this trial, it should not be inferred that this can be applied blindly and without minimization of other forms of stress within limit-feeding management systems.

\section{ACKNOWLEDGMENTS}

Mention of trade names or commercial products in this article is solely for the purpose of providing specific information, and does not imply either recommendation or endorsement by the U.S. Department of Agriculture. The USDA is an equal opportunity provider and employer. This research was supported through appropriated USDA-ARS CRIS funds (Project \#509012630-005-00D). The authors have not stated any conflicts of interest.

\section{REFERENCES}

AOAC. 1990. Official method \#920.29. Official Methods of Analysis. 15th ed. Association of Official Analytical Chemists, Arlington, VA.

AOAC International. 1998. Official method \#988.05. Official Methods of Analysis. 16th ed. AOAC International, Arlington, VA.

Coblentz, W. K., N. M. Esser, P. C. Hoffman, and M. S. Akins. 2015. Growth performance and sorting characteristics of corn silagealfalfa haylage diets with or without forage dilution offered to replacement Holstein dairy heifers. J. Dairy Sci. 98:8018-8034. https://doi.org/10.3168/jds.2015-9491.

Coblentz, W. K., P. C. Hoffman, N. M. Esser, and M. G. Bertram. 2012. Using eastern gamagrass to construct diets that limit intake and caloric density for dairy replacement heifers. J. Dairy Sci. 95:6057-6071. https://doi.org/10.3168/jds.2012-5686.

Cook, N. B., T. B. Bennett, and K. V. Nordlund. 2005. Monitoring indices of cow comfort in free-stall housed dairy herds. J. Dairy Sci. 88:3876-3885. https://doi.org/10.3168/jds.S0022-0302(05)73073 $-3$.

Cook, N. B., and D. J. Reinemann. 2007. A toolbox for assessing cow, udder, and teat hygiene. Pages 31-43 in Proc. 46th Annual Mtg. Natl. Mastitis Council, San Antonio, TX. Natl. Mastitis Council, Madison, WI.

DeVries, T. J., and M. A. G. von Keyserlingk. 2009. Competition for feed affects the feeding behavior of growing dairy heifers. J. Dairy Sci. 92:3922-3929. https://doi.org/10.3168/jds.2008-1934.

Esser, N. M., P. C. Hoffman, W. K. Coblentz, M. W. Orth, and K. A. Weigel. 2009. The effect of dietary phosphorus on bone development in dairy heifers. J. Dairy Sci. 92:1741-1749. https://doi.org/ 10.3168/jds.2008-1789

Goering, H. K., and P. J. Van Soest. 1970. Pages 8-11 in Forage Fiber Analyses (Apparatus, Reagents, Procedures, and Some Applications). Agric. Handbook No. 379. USDA-ARS, Washington, DC.

Greter, A. M., T. J. DeVries, and M. A. G. von Keyserlingk. 2008. Nutrient intake and feeding behavior of growing dairy heifers: effects of dietary dilution. J. Dairy Sci. 91:2786-2795. https://doi.org/10 $.3168 /$ jds.2008-1052.

Greter, A. M., K. E. Leslie, G. J. Mason, B. W. McBride, and T. J. DeVries. 2010. Effect of feed delivery method on the behavior and growth of dairy heifers. J. Dairy Sci. 93:1668-1676. https://doi .org/10.3168/jds.2009-2844.

Hill, T. M., H. G. Bateman III, J. D. Quigley III, J. M. Aldrich, R. L. Schlotterbeck, and A. J. Heinrichs. 2013. Review: New information on the protein requirements and diet formulation for dairy calves and heifers since the Dairy NRC 2001. Prof. Anim. Sci. 29:199207. https://doi.org/10.15232/S1080-7446(15)30225-4. 
Hoffman, P. C. 1997. Optimum body size of Holstein replacement heifers. J. Anim. Sci. 75:836-845. https://doi.org/10.2527/1997 $.753836 \mathrm{x}$.

Hoffman, P. C., N. M. Brehm, S. G. Price, and A. Prill-Adams. 1996 Effect of accelerated postpubertal growth and early calving on lactation performance of primiparous Holstein heifers. J. Dairy Sci. 79:2024-2031. https://doi.org/10.3168/jds.S0022-0302(96)76575 $-\mathrm{X}$.

Hoffman, P. C., C. R. Simson, and M. Wattiaux. 2007. Limit feeding of gravid Holstein heifers: Effect on growth, manure nutrient excretion, and subsequent early lactation performance. J. Dairy Sci. 90:946-954. https://doi.org/10.3168/jds.S0022-0302(07)71578-3.

Hoffman, P. C., K. A. Weigel, and R. M. Wernberg. 2008. Evaluation of equations to predict dry matter intake of dairy heifers. J. Dairy Sci. 91:3699-3709. https://doi.org/10.3168/jds.2007-0644.

Huzzey, J. M., T. J. DeVries, P. Valois, and M. A. G. von Keyserlingk. 2006. Stocking density and feed barrier design affect the feeding and social behavior of dairy cattle. J. Dairy Sci. 89:126-133. https: //doi.org/10.3168/jds.S0022-0302(06)72075-6.

Kertz, A. F., B. A. Barton, and L. F. Reutzel. 1998. Relative efficiencies of wither height and body weight increase from birth until first calving in Holstein cattle. J. Dairy Sci. 81:1479-1482. https://doi .org/10.3168/jds.S0022-0302(98)75712-1.

Kitts, B. L., I. J. H. Duncan, B. W. McBride, and T. J. DeVries. 2011. Effect of the provision of a low-nutritive feedstuff on the behavior of dairy heifers limit fed a high-concentrate ration. J. Dairy Sci. 94:940-950. https://doi.org/10.3168/jds.2010-3767.

Kruse, K. A., D. K. Combs, N. M. Esser, W. K. Coblentz, and P. C. Hoffman. 2010. Evaluation of potential carryover effects associated with limit feeding gravid Holstein heifers. J. Dairy Sci. 93:53745384. https://doi.org/10.3168/jds.2010-3401.

Loerch, S. C. 1990. Effects of feeding growing cattle high-concentrate diets at a restricted intake on feedlot performance. J. Anim. Sci. 68:3086-3095. https://doi.org/10.2527/1990.68103086x.

Longenbach, J. I., A. J. Heinrichs, and R. E. Graves. 1999. Feed bunk length requirements for Holstein dairy heifers. J. Dairy Sci. 82:99 109. https://doi.org/10.3168/jds.S0022-0302(99)75214-8.

Moody, M. L., G. I. Zanton, J. M. Daubert, and A. J. Heinrichs. 2007. Nutrient utilization of differing forage to concentrate ratios by growing Holstein heifers. J. Dairy Sci. 90:5580-5586. https://doi .org $/ 10.3168 / \mathrm{jds} .2007-0570$

NRC. 2001. Nutrient Requirements of Dairy Cattle. 7th rev. ed. National Academy Press, Washington, DC.
Peters, J. B. 2013. Lab procedures and methods. Accessed Feb. 21, 2020. https://uwlab.soils.wisc.edu/about-us/lab-procedures-and -methods/.

Schulte, E. E., J. B. Peters, and P. R. Hodgson. 1987. Wisconsin procedures for soil testing, plant analysis and feed and forage analysis. Dept. Soil Sci. Bull. No. 6. University of Wisconsin, Madison, WI

St-Pierre, N. R. 2007. Design and analysis of pen studies in the animal sciences. J. Dairy Sci. 90(E-Suppl.): E87-E89. https://doi.org/10 .3168/jds.2006-612.

Van Soest, P. J., J. B. Robertson, and B. A. Lewis. 1991. Methods for dietary fiber, neutral detergent fiber, and nonstarch polysaccharides in relation to animal nutrition. J. Dairy Sci. 74:3583-3597. https://doi.org/10.3168/jds.S0022-0302(91)78551-2.

Wildman, E. E., G. M. Jones, P. E. Wagner, R. L. Boman, H. F. Troutt Jr., and T. N. Lesch. 1982. A dairy cow body condition scoring system and its relationship to selected production characteristics. J. Dairy Sci. 65:495-501. https://doi.org/10.3168/jds .S0022-0302(82)82223-6.

Zanton, G. I., and A. J. Heinrichs. 2007. The effects of controlled feeding of a high-forage or high-concentrate ration on heifer growth and first lactation milk production. J. Dairy Sci. 90:3388-3396. https://doi.org/10.3168/jds.2007-0041.

Zanton, G. I., and A. J. Heinrichs. 2008. Rumen digestion and nutritional efficiency of dairy heifers limit-fed a high forage ration to four levels of dry matter intake. J. Dairy Sci. 91:3579-3588. https: //doi.org/10.3168/jds.2008-1210.

Zanton, G. I., and A. J. Heinrichs. 2009. Review: limit-feedingwith altered forage-to-concentrate levels in dairy heifer diets. Prof. Anim. Sci. 25:393-403. https://doi.org/10.15232/S1080-7446(15)30740-3.

Zanton, G. I., and A. J. Heinrichs. 2016. Precision Feeding Dairy Heifers: Strategies And Recommendations. \#DAS 08-130. Penn State College of Agricultural Sciences Cooperative Extension, University Park, PA.

\section{ORCIDS}

W. K. Coblentz $\odot$ https://orcid.org/0000-0003-2477-3449

M. S. Akins (1) https://orcid.org/0000-0001-5517-1681

N. M. Esser @ https://orcid.org/0000-0003-2021-691X 